\title{
FLORA VASCULAR DE UM REMANESCENTE DE FLORESTA ESTACIONAL SEMIDECIDUAL, NO MUNICÍPIO DE MARINGÁ, PARANÁ, BRASIL
}

\author{
Letícia Mônica Garcia* \\ Mariza Barion Romagnolo** \\ Luiz Antonio de Souza***
}

RESUMO: Objetivou-se inventariar e caracterizar a composição florística de um remanescente florestal e contribuir com o conhecimento da flora do Estado do Paraná. As coletas de material botânico foram realizadas entre maio de 2009 e outubro de 2011, e em junho de 2014, por meio de caminhadas aleatórias. Foram coletadas amostras de indivíduos: arbóreos, arbustivos, herbáceos, lianas e epífitas. O material coletado foi herborizado de acordo com os métodos usuais e incorporado no acervo do HUEM. A identificação foi realizada com emprego de bibliografia específica e por comparação com o material do acervo do HUEM e HCF, seguindose o sistema APG III para famílias de angiospermas. Foram coletados e identificados 279 táxons, distribuídos em 66 famílias, 213 gêneros e 244 espécies. As famílias com maior número de espécies foram: Fabaceae (31), Asteraceae (24), Solanaceae (15), Sapindaceae (12), Euphorbiaceae e Malvaceae (11), Myrtaceae (10), Bignoniaceae (9), Rutaceae (8), Apocynaceae, Malpighiaceae, Meliaceae, Piperaceae e Rubiaceae (7). Nessas famílias estão contidas 59,5\% das espécies. Quanto ao hábito, o arbóreo foi predominante, com 107 indivíduos (38,4\%), 95,5\% (236 spp.) das espécies são nativas e apenas 4,5\% (11 spp.) são naturalizadas. Nove espécies encontramse na lista da flora ameaçadas de extinção. Neste estudo foi apurada uma elevada diversidade florística, similar a resultados obtidos por outros autores em áreas de domínio da Floresta Estacional Semidecidual.

PALAVRAS-CHAVE: Angiospermas; Diversidade; Espécies nativas; Levantamento florístico.

Doutoranda do Programa de Pós-graduação em Biologia Comparada da Universidade Estadual de Maringá (UEM), Paraná, Brasil. E-mail: leticia1_monica@hotmail.com

** Docente Doutora do Departamento de Ciências Biológicas da Universidade Estadual de Maringá (UEM), Paraná, Brasil.

*** Docente da Universidade Estadual de Maringá (UEM) e orientador em Programa de Pós-Graduação Stricto Sensu em Ecologia de Ambientes Aquáticos Continentais e em Biologia Comparada na UEM 


\section{VASCULAR FLORA OF A SEASONAL SEMIDECIDUAL FOREST REMNANT IN MARINGÁ, BRAZIL}

ABSTRACT: The floristic composition of a remnant forest is characterized and will contribute towards knowledge on flora of the state of Paraná, Brazil. Botanic material was collected between May 2009 and October 2011 and in June 2014 by randomized rambling. Arboreal, shrub, herbaceous, liana and epiphytes specimens were collected, pressed following the usual methods and deposited at HUEM. Specific bibliography identified the flora collected and compared to the material deposited at HUEM and HCF, following APG III system for angiosperms. Further, 279 taxa were collected and identified, comprising 66 families, 213 genera and 244 species. The families with the largest number of species were Fabaceae (31), Asteraceae (24), Solanaceae (15), Sapindaceae (12), Euphorbiaceae and Malvaceae (11), Myrtaceae (10), Bignoniaceae (9), Rutaceae (8), Apocynaceae, Malpighiaceae, Meliaceae, Piperaceae and Rubiaceae (7). The above mentioned families comprised $59.5 \%$ of the species. Arboreal plants were predominant, with 107 specimens (38.4\%); 95.5\% (236 spp.) of the species were native plants and only $4.5 \%$ (11 spp.) were naturalized. Nine species are on the endangered list. Current analysis revealed high floristic diversity, similar to that by other authors who researched Semidecidual Seasonal Forests.

KEY WORDS: Angiosperms; Diversity; Native species; Floral survey.

\section{INTRODUÇÃO}

Ao longo da história do Brasil, a vegetação natural vem sendo substituída para dar lugar, principalmente à expansão das áreas agrícolas e à pecuária. Em quase todas as atividades, novas áreas são abertas, devido à necessidade de aumentar a produção (SILVA et al., 2003). Assim, o rápido crescimento da industrialização, da urbanização e da agricultura intensiva, teve como consequências o mais extenso e profundo impacto sobre os ecossistemas (VACCARO et al., 1999).

Segundo Maack (1981), até o início do século XX, o Estado do Paraná apresentava 83,41\% de sua área coberta por florestas, já em 1968, a vegetação florestal nativa resumia-se a remanescentes fragmentados e reduzidos, apresentando uma cobertura bastante alterada. Com o avanço do processo de ocupação, degradação e fragmentação, restam apenas 8\% da cobertura florestal (FUNDAÇÃO S.O.S MATA ATLÂNTICA; INPE, 2009). 
O principal exemplo do processo de degradação e fragmentação dos ecossistemas tropicais é representado pela Floresta Estacional Semidecidual (DURIGAN et al., 2000). E os poucos remanescentes preservados possuem grande valor ecológico e taxonômico (DEL QUIQUI et al., 2007). O processo de fragmentação pode provocar às espécies limitação para dispersão e colonização, aumentando a vulnerabilidade à invasão de espécies exóticas e invasoras (PINTO; BRITO, 2005; CAMPOS, 2006).

A fragmentação introduz uma série de novos fatores na história evolutiva de populações naturais de plantas e animais (FACCIULO, 2008). Mas, apesar das consequências provocadas pelo processo de fragmentação dos habitats, os remanescentes possuem fundamental função ecológica, na paisagem local e regional, a partir de suas características de potenciais fontes de propágulos, polinizadores e dispersores no estabelecimento de vegetação. Em alguns casos, uma única árvore sobrevivente, ou um bando de animais, pode conter um material genético precioso e raro (NOGUEIRA-NETO, 2003).

Com isso, para executar projetos de conservação, é necessário que se conheça o ecossistema onde se irá atuar, suas limitações e sua capacidade de recuperação e para isso se deve conhecer as composições florística e faunística, tanto em termos qualitativos como quantitativos (MARACAJÁ et al., 2003). A identidade das espécies é o começo para a compreensão de todo o processo de um ecossistema (MARANGON et al., 2003).

Dentro deste contexto, objetivou-se com este trabalho inventariar a composição florística, de um remanescente florestal, localizado na fazenda do UNICESUMAR, e contribuir com o conhecimento da flora do Estado do Paraná, podendo subsidiar futuras estratégias de conservação e preservação da área em estudo.

\section{MATERIAL E MÉTODOS}

\section{1 ÁREA DE ESTUDO}

A área de estudo constitui um remanescente florestal, pertencente à Fazenda Escola do Centro Universitário de Maringá (UNICESUMAR), com aproximadamente 
58 ha, localizados na margem esquerda do Córrego Morangueiro, Estrada denominada Morangueira próxima à rodovia PR-317 no Município de Maringá,

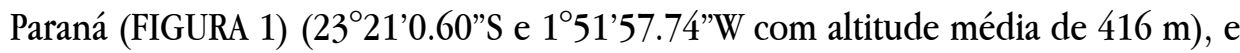
Figura 2 mostrando uma foto aérea da área de estudo.

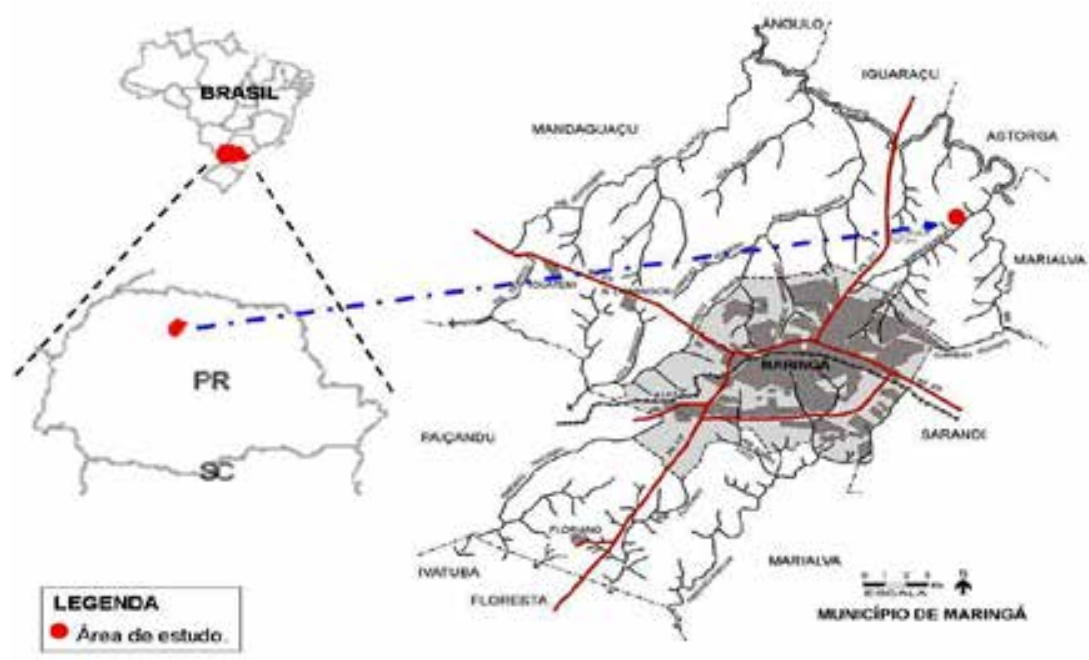

Figura 1. Localização da área de estudo. Remanescente florestal da Fazenda Escola do UNICESUMAR, Município de Maringá, Paraná 


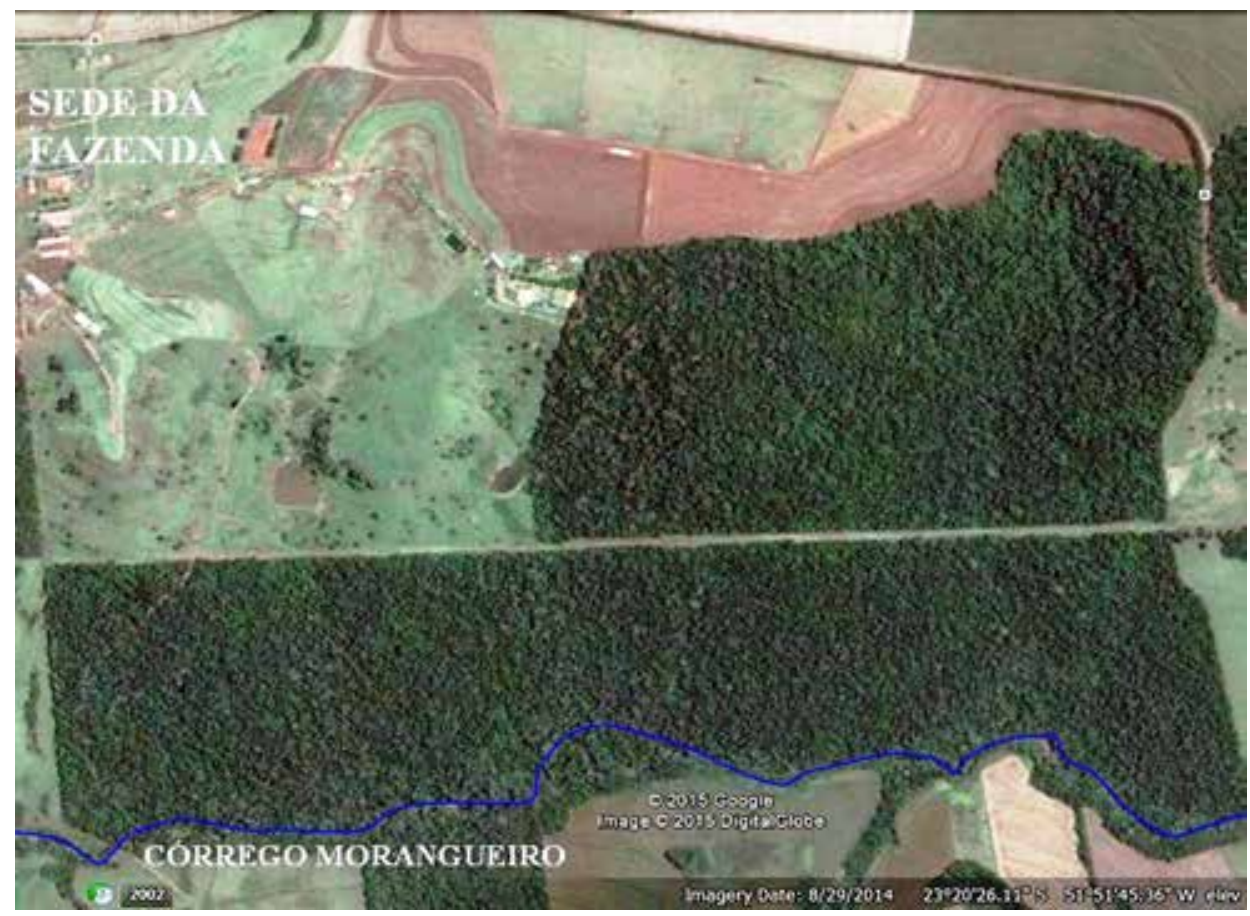

Figura 2. Vista geral da área de estudo, remanescente florestal da Fazenda Escola do UNICESUMAR. Maringá, Paraná.

Fonte: GOOGLE EARTH®, 2014.

De acordo com a classificação de Köppen o clima da região é do tipo CfaClima Subtropical Mesotérmico, com média do mês mais quente superior a $22{ }^{\circ} \mathrm{C}$ e do mês mais frio inferior a $18{ }^{\circ} \mathrm{C}$, sem estação seca definida, com verão quente e geadas menos frequentes (IAPAR, 2014).

O solo da região de Maringá, de acordo com sua formação geológica, pode ser identificado como basáltico com solos lateríticos, popularmente conhecidos por Terra Roxa, de cor vermelho-arroxeada e solos lateríticos erodidos e também Arenito Caiuá com solos lateríticos arenosos, de cor vermelho-arroxeada e solos lateríticos lexiviados (lavados) e pzolizados (acinzentados) dos declives erodidos (EMBRAPA, 2013).

A vegetação da região está inserida no Domínio Fitogeográfico Mata Atlântica (EMBRAPA, 2013), e na Região Fitoecológica da Floresta Estacional Semidecidual 
(FES), sendo que o remanescente em estudo é composto por formações de FES Submontana e Aluvial. O trecho de FES Submontada apresenta-se mais conservado, isolado através de cercas de arame, e o trecho de Aluvial, mais degradado, pois passa por frequentes enchentes, sendo uma parte pisoteada por gado. Em geral a área apresenta uma vegetação fechada, formada por agrupamentos densos com árvores e arbustos, cipós (trepadeiras) e pouca vegetação rasteira. A ocupação do solo do entorno é a pecuária e a agricultura com produção das culturas de soja e milho.

\subsection{COLETA DO MATERIAL EM CAMPO E PREPARAÇÃO EM LABORATÓRIO}

Para o levantamento florístico foram realizadas expedições ao remanescente florestal, distribuídas inicialmente entre os meses de maio de 2009 a outubro de 2011, e em junho de 2014 (sendo 11 coletas em 2009, 24 em 2010, 10 em 2011 e $02 \mathrm{em} 2014$ ). As coletas foram realizadas por meio de caminhadas aleatórias, onde foram amostrados os indivíduos em estádio reprodutivo e vegetativo.

O material foi coletado e herborizado seguindo técnicas usuais (JUDD et al., 2009) e acervadas no Herbário da Universidade Estadual de Maringá (HUEM). Para classificação do porte (arbóreo, arbustivo, herbáceo, liana ou epífita) foram observadas características próprias de cada espécie e as definições de Font Quer (1985).

A identificação taxonômica foi realizada por meio de consulta à bibliografia especializada, sites como o Herbário Virtual do Reflora (2013), por comparação do acervo do HUEM e do Herbário da Universidade Tecnológica Federal do Paraná Campus Campo Mourão (HCF), sendo alguns materiais identificados por especialistas.

Para a organização das espécies e gêneros em famílias empregou-se o sistema de classificação de APG III (2009), e adaptações à classificação de Cronquist (1993), a correção dos nomes científicos e dos autores foi realizada por meio dos sites Flora do Brasil (2014), The Plant List (2013) e The Royal Botanic Gardens Kew (IPNI, 2014).

As espécies foram classificadas quanto ao grau de ameaça, nas categorias em "perigo", "vulneráveis" e "raras", por meio de consulta a The International Union for 
Conservation of Nature (IUCN, 2014), Lista Oficial das Espécies da Flora Brasileira Ameaçada de Extinção (MMA, 2008) e Lista Vermelha da Flora do Estado do Paraná (IAP, 2008).

Para classificação em nativa ou exótica, foram consultadas bibliografias que citam espécies nativas (CARVALHO, 2003; LORENZI, 2002), e a Lista de Espécies da Flora do Brasil (2014), e para as espécies exóticas (LORENZI et al., 2003), e a lista das espécies exóticas com potencial de invasora para a Estado do Paraná (IAP, 2009).

\section{RESULTADO E DISCUSSÃO}

Foram registrados 279 táxons, distribuídas em 66 famílias, 213 gêneros e 244 espécies, sendo que dois táxons não foram identificados em nível de família, seis em nível de gênero e 27 em nível de espécie (Quadro 1), compreendendo indivíduos arbóreos, arbustivos, herbáceos, lianas e epífitas. Foram registrados quatro táxons pertencentes ao grupo das pteridófitas e 275 a flora vascular.

Quadro 1. Relação de famílias, gêneros e espécies de plantas vasculares, coletadas entre os meses de maio de 2009 a outubro de 2011, e em junho de 2014, com seu respectivo nome popular, hábito $=\mathrm{HB}(\mathrm{ARBO}=$ arbórea; $\mathrm{ARBU}=$ arbustiva; $\mathrm{HERB}=$ herbácea; $\mathrm{LIAN}=$ liana; EPIF = epífita), e número de registro no Herbário HUEM. Remanescente florestal da Fazenda Escola do UniCesumar, Maringá, Paraná

(continua)

\begin{tabular}{|l|l|c|c|}
\hline FAMÍLIA/ESPÉCIES & NOME POPULAR & HB & HUEM \\
\hline ANEMIACEAE & & & \\
\hline Anemia phyllitidis (L.) Sw. & & EPIF & 28502 \\
\hline POLYPODIACEAE & & & \\
\hline Pleopeltis angusta Humb. \& Bonpl. ex Willd. & Samambaia & EPIF & 28497 \\
\hline Polypodium polypodioides (L.) Watt & & EPIF & 28490 \\
\hline PTERIDACEAE & & & \\
\hline Doryopteris concolor (Langsd. \& Fisch.) Kuhn & & EPIF & 28491 \\
\hline ACANTHACEAE & & & \\
\hline
\end{tabular}


(continuação)

\begin{tabular}{|c|c|c|c|}
\hline FAMÍLIA/ESPÉCIES & NOME POPULAR & HB & HUEM \\
\hline Aphelandra longiflora (Lindl.) Profice & & ARBU & 22962 \\
\hline Justicia brasiliana Roth & $\begin{array}{l}\text { Junta-de-cobra- } \\
\text { vermelha }\end{array}$ & ARBU & 22196 \\
\hline Justicia lythroides (Nees) V.A.W.Graham & & HERB & 22963 \\
\hline Ruellia angustiflora (Nees) Lindau ex Rambo & & ARBU & 22960 \\
\hline Ruellia erytbropus (Nees) Lindau & & HERB & 22964 \\
\hline Ruellia sp. & & HERB & 22874 \\
\hline \multicolumn{4}{|l|}{ ACHATOCARPACEAE } \\
\hline Achatocarpus praecox Griseb. & & ARBO & 22991 \\
\hline \multicolumn{4}{|l|}{ AMARANTHACEAE } \\
\hline Alternanthera tenella Colla & Apaga-fogo & HERB & 20815 \\
\hline Amaranthus retroflexus $\mathrm{L}$ & Caruru & HERB & 22965 \\
\hline Celosia spicata Spreng. & & HERB & 22966 \\
\hline Chamissoa altissima (Jacq.) Kunth & & LIAN & 22856 \\
\hline Hebanthe eriantha (Poir.) Pedersen & & HERB & 23012 \\
\hline \multicolumn{4}{|l|}{ ANACARDIACEAE } \\
\hline Mangifera indica $\mathrm{L} . *$ & Mangueira & ARBO & VEGET \\
\hline Schinus terebintbifolius Raddi & Falsa-aroeira & ARBO & 20538 \\
\hline \multicolumn{4}{|l|}{ ANNONACEAE } \\
\hline Annona rugulosa (Schltdl.) H.Rainer ** & & ARBO & 22967 \\
\hline Annona sylvatica A.St.-Hil. & Araticum-do-mato & ARBO & 23455 \\
\hline \multicolumn{4}{|l|}{ APIACEAE } \\
\hline $\begin{array}{l}\text { Apium leptophyllum (Pers.) F.Muell. ex } \\
\text { Benth.** }\end{array}$ & & HERB & 23236 \\
\hline \multicolumn{4}{|l|}{ APOCYNACEAE } \\
\hline Asclepias curassavica $\mathrm{L}$. & Falsa-erva-de-rato & HERB & 22969 \\
\hline Aspidosperma polyneuron Müll.Arg. & Peroba- rosa & ARBO & VEGET \\
\hline
\end{tabular}




\begin{tabular}{|c|c|c|c|}
\hline FAMÍLIA/ESPÉCIES & NOME POPULAR & HB & HUEM \\
\hline Forsteronia glabrescens Müll.Arg. & & LIAN & 22968 \\
\hline Forsteronia thyrsoidea (Vell.) Müll.Arg. & & LIAN & 22201 \\
\hline Forsteronia sp. & & LIAN & 22828 \\
\hline Prestonia riedelii (Müll.Arg.) Markgr.** & & LIAN & 22838 \\
\hline Tabernaemontana catharinensis A.DC. & Leiteiro & ARBO & 23245 \\
\hline \multicolumn{4}{|l|}{ ARACEAE } \\
\hline Philodendron sp. & Imbé & EPIF & VEGET \\
\hline \multicolumn{4}{|l|}{ ARALIACEAE } \\
\hline Hydrocotyle leucocepbala Cham. \& Schltdl. & Violinha & HERB & 22970 \\
\hline \multicolumn{4}{|l|}{ ARECACEAE } \\
\hline Syagrus romanzoffiana (Cham.) Glassman & Jerivá & ARBO & 22209 \\
\hline \multicolumn{4}{|l|}{ ASTERACEAE } \\
\hline Ageratum conyzoides $\mathrm{L}$. & Mentrasto & HERB & 22976 \\
\hline $\begin{array}{l}\text { Austroeupatorium inulaefolium (Kunth) } \\
\text { R.M.King \& H.Rob. }\end{array}$ & & ARBU & 22971 \\
\hline Baccharis dracunculifolia DC. & Alecrim-do-campo & ARBU & 22219 \\
\hline Baccharis sp. & & ARBU & 24066 \\
\hline Chaptalia nutans (L.) Pol. & Paraqueda & HERB & 20453 \\
\hline $\begin{array}{l}\text { Clibadium armani (Balb.) Sch.Bip. ex } \\
\text { O.E.Schulz ** }\end{array}$ & & ARBU & 24086 \\
\hline $\begin{array}{l}\text { Chromolaena maximilianii (Schrad. ex DC.) R. } \\
\text { M. King \& H.Rob. }\end{array}$ & Mata-pasto & ARBU & 22834 \\
\hline Chromolaena sp. & & ARBU & 28488 \\
\hline $\begin{array}{l}\text { Critonia megaphylla (Baker) R.M.King \& } \\
\text { H.Rob. ** }\end{array}$ & & $\mathrm{ARBU}$ & 23250 \\
\hline Dasyphyllum brasiliense (Spreng.) Cabrera ** & & ARBU & 28503 \\
\hline Dasyphyllum spinescens (Less.) Cabrera** & & ARBU & 22232 \\
\hline Eclipta prostrata (L.) L. & Erva-botão & HERB & 22879 \\
\hline
\end{tabular}


(continuação)

\begin{tabular}{|c|c|c|c|}
\hline FAMÍLIA/ESPÉCIES & NOME POPULAR & HB & HUEM \\
\hline Elephantopus mollis Kunth & Pé-de-elefante & HERB & 22878 \\
\hline Elephantopus sp. & & HERB & 22975 \\
\hline $\begin{array}{l}\text { Exostigma notobellidiastrum (Griseb.) } \\
\text { G.Sancho }\end{array}$ & & HERB & 22978 \\
\hline Hebeclinium macrophyllum (L.) DC.** & & ARBU & 22972 \\
\hline Senecio brasiliensis (Spreng.) Less. & Berneira & HERB & 22979 \\
\hline Smallanthus sp. & & ARBU & 22973 \\
\hline Spilanthes acmella (L.) Murr*** & Botão-de-ouro & HERB & 22977 \\
\hline Tridax procumbens $\mathrm{L}$. & Erva-de-touro & HERB & 22974 \\
\hline Vernonanthura brasiliana (L.) H.Rob. & & ARBU & 24077 \\
\hline Vernonanthura sp. & & ARBU & 22825 \\
\hline Indeterminada 1 & & ARBU & 22880 \\
\hline Indeterminada 2 & & ARBU & 24087 \\
\hline \multicolumn{4}{|l|}{ BALSAMINACEAE } \\
\hline Impatiens walleriana Hook.f. * & Beijinho & HERB & 22860 \\
\hline \multicolumn{4}{|l|}{ BIGNONIACEAE } \\
\hline Adenocalymma marginatum (Cham.) DC. & & LIAN & 22836 \\
\hline Fridericia chica (Bonpl.) L.G.Lohmann & & LIAN & 22980 \\
\hline Fridericia sp. & & LIAN & 24091 \\
\hline Jacaranda micrantha Cham. & Carobinha & ARBO & VEGET \\
\hline Pyrostegia venusta (Ker Gawl.) Miers & Cipó-de-são-joão & LIAN & 24075 \\
\hline Tecoma stans (L.) Juss. ex Kunth* & Amarelinho & ARBO & 22597 \\
\hline Tynanthus micrantbus Corr.Méllo ex K.Schum. & & LIAN & 22981 \\
\hline Indeterminada 1 & & LIAN & 24067 \\
\hline Indeterminada 2 & & LIAN & 28500 \\
\hline BORAGINACEAE & & & \\
\hline
\end{tabular}




\begin{tabular}{|c|c|c|c|}
\hline \multicolumn{4}{|c|}{ (continuação) } \\
\hline FAMÍLIA/ESPÉCIES & NOME POPULAR & HB & HUEM \\
\hline Cordia americana (L.) Gottschling \& J.S.Mill. & Guajuvira & $\mathrm{ARBO}$ & 22983 \\
\hline Cordia ecalyculata Vell. & Café-de-bugre & $\mathrm{ARBO}$ & 22203 \\
\hline Cordia trichotoma (Vell.) Arráb. ex Steud. & Louro-pardo & $\mathrm{ARBO}$ & 22845 \\
\hline Heliotropium lanceolatum Ruiz \& Pav.** & & HERB & 24094 \\
\hline \multicolumn{4}{|l|}{ CACTACEAE } \\
\hline Pereskia aculeata Mill. & Orapronóbis & LIAN & 22859 \\
\hline Rhipsalis cereuscula Haw. & Cacto & EPIF & 22984 \\
\hline \multicolumn{4}{|l|}{ CANNABACEAE } \\
\hline Celtis iguanaea (Jacq.) Sarg. & Sarã & & 22985 \\
\hline Trema micrantha (L.) Blume & Grandiúva & $\mathrm{ARBO}$ & 20459 \\
\hline \multicolumn{4}{|l|}{ CARDIOPTERIDACEAE } \\
\hline Citronella paniculata (Mart.) R.A.Howard & falsa-mate & $\mathrm{ARBO}$ & 22988 \\
\hline \multicolumn{4}{|l|}{ CARICACEAE } \\
\hline Carica papaya L.* & Mamoeiro & $\mathrm{ARBO}$ & VEGET \\
\hline Jaracatia spinosa A.DC. & Jaracatiá & $\mathrm{ARBO}$ & VEGET \\
\hline \multicolumn{4}{|l|}{ CELASTRACEAE } \\
\hline Hippocratea volubilis $\mathrm{L}$. & Fava-de-arara & LIAN & 20542 \\
\hline Maytenus aquifolium Mart. & Espinheira-santa & $\mathrm{ARBO}$ & 24079 \\
\hline Maytenus dasyclada Mart.** & & ARBU & 23126 \\
\hline Maytenus ilicifolia Mart. ex Reissek** & & $\mathrm{ARBO}$ & VEGET \\
\hline \multicolumn{4}{|l|}{ COMBRETACEAE } \\
\hline Combretum fruticosum (Loefl.) Stuntz & Pombeiro & LIAN & 22989 \\
\hline Terminalia sp. & & $\mathrm{ARBO}$ & VEGET \\
\hline \multicolumn{4}{|l|}{ COMMELINACEAE } \\
\hline Commelina benghalensis $\mathrm{L}$. & & HERB & 28484 \\
\hline
\end{tabular}


(continuação)

\begin{tabular}{|c|c|c|c|}
\hline FAMÍLIA/ESPÉCIES & NOME POPULAR & HB & HUEM \\
\hline $\begin{array}{l}\text { Dichorisandra bexandra (Aubl.) Kuntze ex } \\
\text { Hand.-Mazz. }\end{array}$ & & HERB & 22883 \\
\hline \multicolumn{4}{|l|}{ CONVOLVULACEAE } \\
\hline Merremia tuberos $a$ (L.) Rendle & Flor-de-madeira & LIAN & VEGET \\
\hline \multicolumn{4}{|l|}{ CUCURBITACEAE } \\
\hline Cayaponia martiana (Cogn.) Cogn. ${ }^{* *}$ & & LIAN & 22816 \\
\hline Melothria pendula $\mathrm{L} . * *$ & & LIAN & 22817 \\
\hline Sicyos polyacanthus Cogn. & Pó-de-mico & LIAN & 24083 \\
\hline \multicolumn{4}{|l|}{ ERYTHROXYLACEAE } \\
\hline Erytbroxylum deciduum A.St.-Hil.*** & Fruta-de-pomba & ARBO & 22189 \\
\hline \multicolumn{4}{|l|}{ EUPHORBIACEAE } \\
\hline Acalypha gracilis Spreng. & Acalifa & ARBU & 22186 \\
\hline Actinostemon concolor (Spreng.) Müll.Arg. & Laranjeira-do-Mato & ARBU & 22998 \\
\hline Alchornea glandulosa Poepp. \& Endl. & Tapiá & ARBO & 28495 \\
\hline Alchornea sidifolia Müll.Arg. & & ARBO & 24084 \\
\hline Dalechampia stipulacea Müll.Arg. & & LIAN & 20545 \\
\hline Euphorbia birta $\mathrm{L}$. & Erva-de-santa-luzia & HERB & 22995 \\
\hline Euphorbia sp. & & HERB & 23115 \\
\hline Gymnanthes klotzschiana Müll.Arg. & Branquilho & ARBO & 22193 \\
\hline Phyllanthus corcovadensis Müll.Arg. ** & & HERB & 22997 \\
\hline Ricinus communis $\mathrm{L} . *$ & Mamona & ARBU & 22868 \\
\hline Manihot grabamii Hook. & & ARBU & 22602 \\
\hline \multicolumn{4}{|l|}{ FABACEAE- CAESALPINIOIDEAE } \\
\hline Baubinia forficata Link** & Pata-de-vaca & ARBO & 23000 \\
\hline Caesalpinia decapetala (Roth) Alston** & & ARBU & 23130 \\
\hline Phanera microstachya (Raddi) L.P.Queiroz & & LIAN & 22887 \\
\hline
\end{tabular}


(continuação)

\begin{tabular}{|c|c|c|c|}
\hline FAMÍLIA/ESPÉCIES & NOME POPULAR & HB & HUEM \\
\hline Holocalyx balansae Micheli & Alecrim & ARBO & 23451 \\
\hline Peltophorum dubium (Spreng.) Taub. & Canafístula & ARBO & 23121 \\
\hline Senna birsuta (L.) H.S.Irwin \& Barneby & Fedegoso & ARBU & 23122 \\
\hline Senna multijuga (Rich.) H.S.Irwin \& Barneby & Pau-cigarra & ARBO & 22813 \\
\hline Senna obtusifolia (L.) H.S.Irwin \& Barneby & Fedegoso & ARBU & 22595 \\
\hline Senna occidentalis (L.) Link & Fedegoso & ARBU & 22820 \\
\hline \multicolumn{4}{|l|}{ FABACEAE- FABOIDEAE } \\
\hline Aeschynomene americana $\mathrm{L}$. & Angiquinho & ARBU & 22891 \\
\hline Crotalaria incana $\mathrm{L}$. & Guiso-de-cascavel & ARBU & 23001 \\
\hline $\begin{array}{l}\text { Dablstedtia mueblbergiana (Hassl.) M. J. Silva } \\
\text { \& A.M.G. Azevedo }\end{array}$ & Feijão-crú & ARBO & 23419 \\
\hline Dalbergia frutescens (Vell.) Britton & Rabo-de-bugio & ARBO & 22865 \\
\hline Desmodium incanum DC. & Pega-pega & ARBU & 23415 \\
\hline Erythrina falcata Benth. & & ARBO & 23233 \\
\hline Indigofera suffruticosa Mill. & & ARBU & 22603 \\
\hline Lonchocarpus campestris Mart. ex Benth. & & ARBO & VEGET \\
\hline Machaerium paraguariense Hassl. & Sapuva & ARBO & 28486 \\
\hline Machaerium stipitatum Vogel & Sapuva & ARBO & 23002 \\
\hline $\begin{array}{l}\text { Macroptilium atropurpureum (Sessé \& Moc. ex } \\
\text { DC.) Urb. }\end{array}$ & & HERB & 22601 \\
\hline Mucuna pruriens (L.) DC. & & LIAN & 23124 \\
\hline Myrocarpus frondosus Allemão & & ARBO & 22233 \\
\hline Sesbania virgata (Cav.) Pers. & & ARBU & 22591 \\
\hline \multicolumn{4}{|l|}{ FABACEAE- MIMOSOIDEAE } \\
\hline Albizia niopoides (Spruce ex Benth.) Burkart & Farinha-seca & ARBO & 23459 \\
\hline Calliandra foliolos $a$ Benth. & Sarandi & ARBO & 23133 \\
\hline Enterolobium contortisiliquum (Vell.) Morong & Timburi & ARBO & 23120 \\
\hline
\end{tabular}


(continuação)

\begin{tabular}{|c|c|c|c|}
\hline FAMÍLIA/ESPÉCIES & NOME POPULAR & HB & HUEM \\
\hline Inga marginata Willd. & Ingá & ARBO & 23119 \\
\hline Inga vera Willd. & Ingá & ARBO & 24080 \\
\hline Leucaena leucocephala (Lam.) de Wit* & Leucena & ARBO & 24082 \\
\hline Parapiptadenia rigida (Benth.) Brenan & Gurucaia & ARBO & 20465 \\
\hline Senegalia polyphylla (DC.) Britton \& Rose & Monjoleiro & ARBO & 24062 \\
\hline \multicolumn{4}{|l|}{ LAMIACEAE } \\
\hline Leonurus sibiricus L. & Rubim & ARBU & 24093 \\
\hline Ocimum gratissimum $\mathrm{L}$. & & ARBU & 23090 \\
\hline \multicolumn{4}{|l|}{ LAURACEAE } \\
\hline Endlicheria paniculata (Spreng.) J. F.Macbr. & Canela-do-brejo & ARBO & 23092 \\
\hline Nectandra grandiflora Nees** & Canela & ARBO & 22598 \\
\hline Nectandra megapotamica (Spreng.) Mez & Canela & ARBO & 24088 \\
\hline Ocotea elegans Mez & Canela & ARBO & 22229 \\
\hline Ocotea puberula (Rich.) Nees & Canela & ARBO & 22187 \\
\hline \multicolumn{4}{|l|}{ LECYTHIDACEAE } \\
\hline Cariniana estrellensis (Raddi) Kuntze & Jequitibá & ARBO & 22200 \\
\hline \multicolumn{4}{|l|}{ LOGANIACEAE } \\
\hline Spigelia pusilla Mart.*** & & HERB & 23093 \\
\hline Spigelia sp. & & HERB & 23232 \\
\hline Strychnos brasiliensis Mart. & Quineira & ARBU & 23085 \\
\hline \multicolumn{4}{|l|}{ LYTHRACEAE } \\
\hline Cuphea carthagenensis (Jacq.) J.Macbr.*** & Sete-sangrias & HERB & 23231 \\
\hline \multicolumn{4}{|l|}{ MALPIGHIACEAE } \\
\hline Alicia anisopetala (A.Juss.) W.R.Anderson & & LIAN & 22833 \\
\hline Dicella nucifera Chodat & Castanha-de-cipó & LIAN & 22599 \\
\hline Heteropterys sp. & & LIAN & 22188 \\
\hline
\end{tabular}


(continuação)

\begin{tabular}{|c|c|c|c|}
\hline FAMÍLIA/ESPÉCIES & NOME POPULAR & HB & HUEM \\
\hline Mascagnia australis C.E.Anderson & & LIAN & 23077 \\
\hline Mascagnia divaricata (Kunth) Nied. & & LIAN & 22600 \\
\hline Indeterminada 1 & & LIAN & 28481 \\
\hline Indeterminada 2 & & LIAN & 22886 \\
\hline \multicolumn{4}{|l|}{ MALVACEAE } \\
\hline Abutilon umbelliflorum A.St.-Hil.*** & & ARBU & 23442 \\
\hline Bastardiopsis densiflora (Hook. \& Arn.) Hassl. & Louro-branco & ARBO & 23443 \\
\hline Byttneria urticifolia K.Schum.** & & ARBU & 23449 \\
\hline Ceiba speciosa (A.St.-Hil.) Ravenna & Paineira-rosa & ARBO & VEGET \\
\hline Heliocarpus popayanensis Kunth & Algodoeiro & ARBO & 23445 \\
\hline Luehea divaricata Mart. \& Zucc. & Açoita-cavalo & ARBO & 24076 \\
\hline Malvastrum americanum (L.) Torr. & Malva-de-espiga & ARBU & 22889 \\
\hline Pavonia sepium A.St.-Hil. & Guanxuma & ARBU & 23448 \\
\hline Sida urens $\mathrm{L}$. & Guanxuma & ARBU & 23110 \\
\hline Triumfetta rbomboidea Jacq. & Carrapichão & ARBU & 23104 \\
\hline Wissadula bernandioides (L.Hér.) Garcke ** & & ARBU & 23447 \\
\hline \multicolumn{4}{|l|}{ MELIACEAE } \\
\hline Cedrela fissilis Vell. & Cedro & ARBO & 22222 \\
\hline Guarea guidonia (L.) Sleumer & Marinheiro & ARBO & 23075 \\
\hline Guarea kuntbiana A.Juss. & Teimoso & ARBO & 23074 \\
\hline Melia azedarach L. & Santa-bárbara & ARBO & 24070 \\
\hline Trichilia catigua A.Juss. & Catiguá & ARBO & 23107 \\
\hline Trichilia elegans A.Juss. & Catiguazinho & ARBO & 22206 \\
\hline Trichilia pallida Sw. & Catiguá & ARBO & 22214 \\
\hline \multicolumn{4}{|l|}{ MORACEAE } \\
\hline Ficus sp. & & ARBO & VEGET \\
\hline
\end{tabular}


(continuação)

\begin{tabular}{|l|l|c|c|}
\hline FAMÍLIA/ESPÉCIES & NOME POPULAR & HB & HUEM \\
\hline Maclura tinctoria (L.) D.Don ex Steud. & Amora-branca & ARBO & 23102 \\
\hline Morus nigra L. & Amora & ARBO & 23249 \\
\hline Sorocea bonplandii (Baill.) W.C.Burger et al. & $\begin{array}{l}\text { Falsa-espinheira- } \\
\text { santa }\end{array}$ & ARBO & 23100 \\
\hline MYRTACEAE & & & \\
\hline Campomanesia guazumifolia (Cambess.) O.Berg & Sete-capotes & ARBO & 24160 \\
\hline Campomanesia xanthocarpa (Mart.) O.Berg & Gabiroba & ARBO & 22220 \\
\hline Eugenia florida DC. & Guamirim & ARBO & 22202 \\
\hline Eugenia involucrata DC.** & & ARBO & 23083 \\
\hline Eugenia pyriformis Cambess. & Uvaia & ARBO & VEGET \\
\hline Eugenia ramboi D.Legrand & & ARBO & 23094 \\
\hline Eugenia repanda O.Berg & Guamirim & ARBO & 22818 \\
\hline Eugenia uniflora L. & Pitanga & ARBO & 23106 \\
\hline Myrcianthes pungens (O. Berg) D. Legrand & Guabiju & ARBO & 28479 \\
\hline Psidium guajava L.* & Goiabeira & ARBO & 23098 \\
\hline NYCTAGINACEAE & & LIAN & 23022 \\
\hline Bougainvillea glabra Choisy & Primavera & ARBO & 20456 \\
\hline Guapira birsuta & Maria-mole & ARBO & 22190 \\
\hline Pisonia aculeata L. & & LIAN & 20811 \\
\hline ONAGRACEAE & Cruz-de-malta & ARBU & 22888 \\
\hline Ludwigia elegans (Cambess.) H.Hara** & & & \\
\hline ORCHIDADECEAE & & HERB & 20814 \\
\hline Aspidogyne kuczynskii (Porsch) Garay & & & \\
\hline PASSIFLORACEAE & & LIAN & 22890 \\
\hline Passiflora capsularis L. & & & \\
\hline Passiflora suberosa L.** & & & \\
\hline
\end{tabular}


(continuação)

\begin{tabular}{|c|c|c|c|}
\hline FAMÍLIA/ESPÉCIES & NOME POPULAR & HB & HUEM \\
\hline \multicolumn{4}{|l|}{ PHYTOLACCACEAE } \\
\hline Gallesia integrifolia (Spreng.) Harms & Pau-d'alho & ARBO & 24081 \\
\hline Phytolacca dioica $\mathrm{L}$. & Cebolão & ARBO & 23010 \\
\hline Rivina bumilis $\mathrm{L}$. & & ARBU & 22882 \\
\hline Seguieria aculeata Jacq. & Limãozinho & ARBO & 20462 \\
\hline Trichostigma octandrum (L.) H.Walter** & & LIAN & 23242 \\
\hline \multicolumn{4}{|l|}{ PICRAMNIACEAE } \\
\hline Picramnia ramiflora Planch. & Camboitá & ARBO & 22212 \\
\hline \multicolumn{4}{|l|}{ PIPERACEAE } \\
\hline Peperomia sp. & & HERB & 28499 \\
\hline Piper aduncum $\mathrm{L}$. & Pimenta-de-macaco & HERB & 24069 \\
\hline Piper amalago $\mathrm{L}$. & Pimenta-de-macaco & ARBU & 22824 \\
\hline Piper mollicomum Kunth & & ARBU & 23238 \\
\hline Piper sp.1 & & HERB & 24090 \\
\hline Piper sp.2 & & ARBU & 23014 \\
\hline Piper sp.3 & & HERB & 23015 \\
\hline \multicolumn{4}{|l|}{ PLANTAGINACEAE } \\
\hline Plantago tomentosa Lam. & Tanchagem & HERB & 23020 \\
\hline \multicolumn{4}{|l|}{ POACEAE } \\
\hline Coix lacryma-jobi $\mathrm{L}$. & Capim-de-lágrima & HERB & 22885 \\
\hline $\begin{array}{l}\text { Megathyrsus maximus (Jacq.) B.K.Simon \& } \\
\text { S.W.L.Jacobs* }\end{array}$ & Capim-colonião & HERB & 20452 \\
\hline Panicum sp. & & HERB & 22842 \\
\hline Pharus lappulaceus Aubl. & Capim & HERB & 28487 \\
\hline $\begin{array}{l}\text { Ocellochloa stolonifera (Poir.) Zuloaga \& } \\
\text { Morrone** }\end{array}$ & & HERB & 23018 \\
\hline POLYGONACEAE & & & \\
\hline
\end{tabular}


(continuação)

\begin{tabular}{|c|c|c|c|}
\hline FAMÍLIA/ESPÉCIES & NOME POPULAR & HB & HUEM \\
\hline Polygonum hydropiperoides Michx. & Erva-de-bicho & HERB & 23011 \\
\hline Ruprechtia laxiflora Meisn. & Marmeleiro & ARBO & 23013 \\
\hline \multicolumn{4}{|l|}{ PORTULACACEAE } \\
\hline Talinum paniculatum (Jacq.) Gaertn. & Maria-gorda & HERB & 23019 \\
\hline \multicolumn{4}{|l|}{ PRIMULACEAE } \\
\hline Myrsine sp. & & ARBO & 23235 \\
\hline \multicolumn{4}{|l|}{ RHAMNACEAE } \\
\hline Gouania sp. & & LIAN & 23411 \\
\hline Rhamnidium elaeocarpum Reissek** & Saguaragi-amarelo & ARBO & 22852 \\
\hline \multicolumn{4}{|l|}{ ROSACEAE } \\
\hline Eryobotrya japonica* & Ameixa & ARBO & VEGET \\
\hline \multicolumn{4}{|l|}{ RUBIACEAE } \\
\hline Geophila macropoda DC. & & HERB & 23035 \\
\hline Geophila repens (L.) I.M.Johnst. & & HERB & 20553 \\
\hline Manettia luteo-rubra (Vell.) Benth. & & LIAN & 20541 \\
\hline Palicourea sp. & & ARBU & 23032 \\
\hline Psychotria carthagenensis Jacq. & Cafezinho & ARBU & 23247 \\
\hline Randia ferox (Cham. \& Schltdl.) DC. & & ARBO & 20812 \\
\hline Richardia brasiliensis Gomes & Poaia-do-campo & HERB & 23034 \\
\hline \multicolumn{4}{|l|}{ RUTACEAE } \\
\hline Balfourodendron riedelianum (Engl.) Engl. & Pau-marfim & ARBO & 23038 \\
\hline Citrus limon (L.) Burm.f.* & Limoeiro & ARBU & 20454 \\
\hline Citrus sp. & & ARBU & 23417 \\
\hline Pilocarpus pennatifolius Lem. & Jaborandi & ARBU & 23243 \\
\hline Zantboxylum fagara (L.) Sarg. & Coentro-do-mato & ARBO & 24060 \\
\hline Zanthoxylum petiolare A.St.-Hil. \& Tul. & Mamica-de-porca & ARBO & 23026 \\
\hline
\end{tabular}


(continuação)

\begin{tabular}{|c|c|c|c|}
\hline FAMÍLIA/ESPÉCIES & NOME POPULAR & HB & HUEM \\
\hline Zanthoxylum rboifolium Lam. & Mamica-de-porca & ARBO & 22811 \\
\hline Zanthoxylum sp. & & ARBO & 23033 \\
\hline \multicolumn{4}{|l|}{ SALICACEAE } \\
\hline Banara tomentosa Clos & & ARBO & 20552 \\
\hline Casearia decandra Jacq. & Guaçatonga & ARBO & 23230 \\
\hline Casearia gossypiosperma Briq. & Espeteiro & ARBO & 23046 \\
\hline Casearia sylvestris $\mathrm{Sw}$. & Guaçatonga & ARBO & 22218 \\
\hline Prockia crucis P.Browne ex L. & Marmeleira & ARBO & 23044 \\
\hline Xylosma sp. & & ARBO & 23424 \\
\hline \multicolumn{4}{|l|}{ SAPINDACEAE } \\
\hline $\begin{array}{l}\text { Allophylus edulis (A.St.-Hil. et al.) Hieron. ex } \\
\text { Niederl. }\end{array}$ & Vacum & ARBO & 23056 \\
\hline Cupania vernalis Cambess. & Camboatã & ARBO & 23071 \\
\hline Diatenopteryx sorbifolia Radlk. & Maria-preta & ARBO & 22217 \\
\hline Matayba elaeagnoides Radlk. & Camboatá & ARBO & 23058 \\
\hline Paullinia meliifolia Juss. & & LIAN & 20466 \\
\hline Serjania fuscifolia Radlk. & & LIAN & 24071 \\
\hline Serjania glabrata Kunth & & LIAN & 23072 \\
\hline Serjania meridionalis Cambess. & & LIAN & 22840 \\
\hline Serjania tristis Radlk.** & & LIAN & 22841 \\
\hline Thinouia mucronata Radlk. & & LIAN & 22884 \\
\hline Urvillea laevis Radlk. & & LIAN & 28482 \\
\hline Urvillea ulmacea Kunth & & LIAN & 23066 \\
\hline \multicolumn{4}{|l|}{ SAPOTACEAE } \\
\hline Chrysophyllum inornatum Mart.** & & ARBO & 22199 \\
\hline $\begin{array}{l}\text { Chrysophyllum gonocarpum (Mart. \& Eichler ex } \\
\text { Miq.) Engl. }\end{array}$ & Guatambu & ARBO & 22225 \\
\hline
\end{tabular}


(continuação)

\begin{tabular}{|c|c|c|c|}
\hline FAMÍLIA/ESPÉCIES & NOME POPULAR & HB & HUEM \\
\hline \multicolumn{4}{|l|}{ SCROPHULARIACEAE } \\
\hline Buddleja stachyoides Cham. \& Schltdl.** & Barbasco & ARBU & 24092 \\
\hline \multicolumn{4}{|l|}{ SMILACACEAE } \\
\hline Smilax campestris Griseb. & Salsaparrilha & LIAN & 22197 \\
\hline \multicolumn{4}{|l|}{ SOLANACEAE } \\
\hline Brunfelsia sp. & & ARBU & 23127 \\
\hline Cestrum intermedium Sendtn. & Coreana & ARBU & 23059 \\
\hline Cestrum strigilatum Ruiz \& Pav. & $\begin{array}{l}\text { Coerana-de-flo- } \\
\text { verde }\end{array}$ & ARBU & 23047 \\
\hline Solanum americanum Mill. & Maria-preta & ARBU & 23065 \\
\hline Solanum asperolanatum Ruiz \& Pav.** & Jurubeba & ARBU & 24166 \\
\hline Solanum capsicoides All.** & Joá & HERB & 22871 \\
\hline Solanum granuloso-leprosum Dunal & Fumo-bravo & ARBU & 20549 \\
\hline Solanum hirtellum (Spreng.) Hassl. & & ARBU & 23418 \\
\hline Solanum pseudocapsicum L.** & Peloteira & ARBU & 20457 \\
\hline Solanum pseudoquina A.St.-Hil.*** & Coerana & ARBO & 23456 \\
\hline Solanum sanctae-catharinae Dunal & & ARBU & 22198 \\
\hline Solanum symmetricum Rusby & & ARBU & 23062 \\
\hline Solanum viarum Dunal & Joá & ARBU & 20550 \\
\hline Solanum sp. & & ARBU & 22592 \\
\hline Vassobia breviflora ( Sendtn. ) Hunz. & & ARBU & 23248 \\
\hline \multicolumn{4}{|l|}{ URTICACEAE } \\
\hline Boebmeria caudata Sw. & Urtiga-mansa & ARBU & 22853 \\
\hline Cecropia glaziovii Snethl. & Embaúba & ARBO & 23244 \\
\hline Urera baccifera (L.) Gaudich. ex Wedd. & Urtiga & ARBU & 23070 \\
\hline \multicolumn{4}{|l|}{ VERBENACEAE } \\
\hline Aloysia virgata (Ruiz \& Pav.) Juss. & Lixeira & ARBO & 20535 \\
\hline Lantana camara $\mathrm{L}$. & Cambára & ARBU & 22609 \\
\hline
\end{tabular}


(conclusão)

\begin{tabular}{|l|l|c|c|}
\hline FAMÍLIA/ESPÉCIES & NOME POPULAR & HB & HUEM \\
\hline Lantana trifolia L.** & Uvinha-do-campo & ARBU & 23054 \\
\hline Petrea volubilis L. & & ARBU & 24073 \\
\hline Stachytarpheta cayennensis (Rich.) Vahl** & Gervão & HERB & 23116 \\
\hline Verbena litoralis Kunth & Felda-terra & HERB & 23039 \\
\hline VIOLACEAE & & & \\
\hline Hybantbus bigibbosus (A.St.-Hil.) Hassl. & Erva-de-veado & ARBU & 22831 \\
\hline INDETERMINADA 1 & & LIAN & 23413 \\
\hline INDETERMINADA 2 & & LIAN & 28546 \\
\hline
\end{tabular}

*plantas exóticas/invasora. **plantas registradas somente neste trabalho Fonte: Dados da pesquisa

As famílias mais representativas quanto ao número de espécies foram Fabaceae com 31, seguida de Asteraceae com 24, Solanaceae com 15, Sapindaceae com 12, Euphorbiaceae e Malvaceae com 11 (Figura 3). Dentre as demais famílias $8,24 \%$ foram representadas por uma espécie cada.

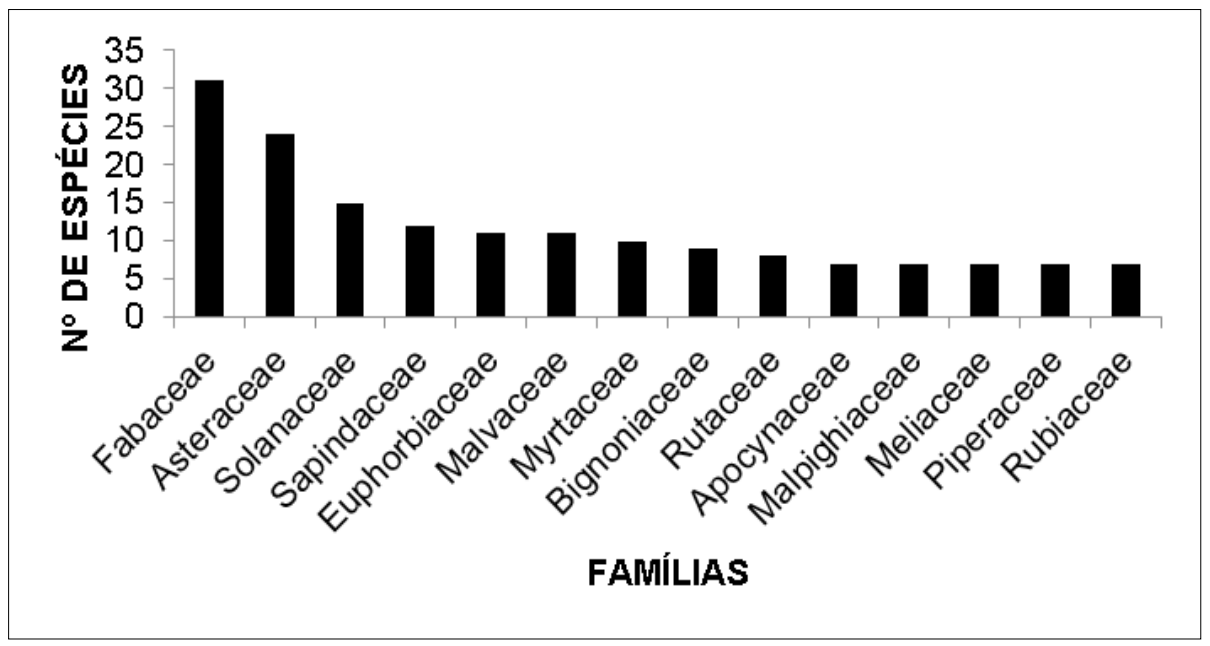

Figura 3. Famílias de maior diversidade específica coletadas no período de maio de 2009 a outubro de 2011, e em junho de 2014. Remanescente florestal da fazenda do UNICESUMAR, no Município de Maringá, Paraná. 
Os resultados do presente estudo, em relação à diversidade de espécies para famílias, são semelhantes aos encontrados em outros remanescentes florestais sob domínio da FES, que utilizaram a mesma metodologia de amostragem incluindo todos os tipos biológicos conforme o Quadro 2.

Quadro 2. Relação das famílias de maior riqueza específica registradas no levantamento florístico do Remanescente Florestal da Fazenda Escola do UNICESUMAR e em outros levantamentos

\begin{tabular}{|l|l|l|l|l|l|l|l|}
\hline $\begin{array}{l}\text { Presente } \\
\text { Estudo }\end{array}$ & $\begin{array}{l}\text { Rossetto; } \\
\text { Vieira } \\
\mathbf{( 2 0 1 3 )}\end{array}$ & $\begin{array}{l}\text { Pereira } \\
\mathbf{( 2 0 1 2 )}\end{array}$ & $\begin{array}{l}\text { Souza; } \\
\text { Monteiro } \\
\mathbf{( 2 0 0 5 )}\end{array}$ & $\begin{array}{l}\text { Slusarski; } \\
\text { Souza (2012) }\end{array}$ & $\begin{array}{l}\text { Souza } \\
\text { et al. } \\
\mathbf{( 1 9 9 7 )}\end{array}$ & $\begin{array}{l}\text { Souza et } \\
\text { al. (2004) }\end{array}$ & $\begin{array}{l}\text { Souza et al. } \\
(\mathbf{2 0 0 9})\end{array}$ \\
\hline Fabaceae & Fabaceae & Fabaceae & Fabaceae & Fabaceae & Fabaceae & Fabaceae & Fabaceae \\
\hline Asteraceae & Asteraceae & Myrtaceae & Myrtaceae & Rubiaceae & Myrtaceae & Rubiaceae & Poaceae \\
\hline Solanaceae & Solanaceae & Rubiaceae & Poaceae & Euphorbiaceae & Rubiaceae & Myrtaceae & Rubiaceae \\
\hline Sapindaceae & Lauraceae & Bignoniaceae & Rubiaceae & Myrtaceae & Poaceae & Lauraceae & Asteraceae \\
\hline Euphorbiaceae & Myrtaceae & Lauraceae & Bignoniaceae & Solanaceae & & Poaceae & Euphorbiaceae \\
\hline
\end{tabular}

Outros levantamentos realizados sob domínio de FES, em áreas mais distantes e de outros Estados, do presente estudo também destacam as famílias Fabaceae, Myrtaceae, Euphorbiaceae, Malvaceae, Rubiaceae, Rutaceae, Sapindaceae, Apocynaceae e Bignoniaceae com grande representatividade (CARVALHO et al., 2000; MARANGON et al., 2003; SILVA; SOARES, 2003; VEIGA et al., 2003; BATTILANI et al., 2005; PEREIRA; ALVES, 2006; BUENO et al., 2007). Esses resultados corroboram com a representatividade destas famílias para esta Região Fitoecológica. De acordo com Leitão-Filho (1987), as famílias mais representativas na mata atlântica são Fabaceae, Myrtaceae, Euphorbiaceae, Rubiaceae, Sapindaceae, Lauraceae, Meliaceae e Rutaceae, conforme observa-se também nesses resultados. Fabaceae representada por 31 espécies foi a de maior diversidade, com 11,11\% das espécies amostradas, sendo que Faboideae ocorreu com 14 espécies, Caesalpinioideae com 09 e Mimosoideae com 08.

Das espécies coletadas da família Bignoniaceae, a maior parte é representada por lianas, e segundo Bigarella e Mazuchowski (1985), as lianas dessa família apresentam elevada representatividade para a FES do Estado do Paraná, sendo 
destacada também nos trabalhos de Souza e Monteiro (2005) na região do alto rio Paraná, município de Porto Rico (PR), e de Zipparro et al. (2005) no Parque Estadual Intervales na Serra de Paranapiacaba em Sete Barras (SP).

Para Souza (1998), a paisagem da Floresta Estacional Semidecidual apresenta-se muito diversificada devido às manchas provocadas pelos diferentes tipos e graus de perturbações, resultantes de cortes seletivos, pisoteio do gado, trilhas e incêndios. Contudo, a diversidade florística da área, avaliada pelo número de famílias e espécies levantadas, é semelhante aos resultados obtidos por Kita et al. (2007), em que foram registradas 79 famílias e 339 espécies; Pereira (2012) verificou 64 famílias e 245 espécies; Slusarski e Souza (2012), 60 famílias e 148 espécies.

Os gêneros de maior diversidade específica foram: Solanum (11 espécies), Eugenia e Piper (6), Senna, Zantboxylum e Serjania (4), reunindo juntos 12,54\% das espécies. Dentre as demais, 06 foram representados por três espécies, 26 por duas espécies e 165 por apenas uma. Outros levantamentos realizados sob domínio da FES também destacam estes gêneros como os mais representativos, Eugenia nos levantamentos de Campos et al. (2006), Pereira (2012), Slusarski e Souza (2012), e Eugenia e Solanum no trabalho de Souza e Monteiro (2005).

Quanto ao hábito, foram registrados: 107 de hábito arbóreo (38,35\%), 71 espécies arbustivo (25,44\%), 49 espécies herbáceo (17,56\%), 46 espécies com hábito trepador (lianas e trepadeiras) (16,48\%) e seis espécies de epífitas (2,15\%). Ao se distribuir as famílias entre os diversos hábitos, pode-se observar que a categoria das arbóreas é a que tem o maior número de representantes, seguidas pelas arbustivas, herbáceas, lianas e epífitas. Em levantamentos de FES que incluiu todos os portes, Stranghetti et al. (2003), Souza e Monteiro (2005), Kita et al. (2007), Pereira (2012), Slusarski e Souza (2012) também relataram o porte arbóreo como mais rico em espécies.

Comparando-se este estudo com os trabalhos de Kita et al. (2007), Souza et al. (2010), Pereira (2012), Slusarski e Souza (2012), Rossetto e Vieira (2013) e IGPlan (2013), 178 espécies também foram encontradas e 41 espécies registradas (Tabela 1). Algumas espécies de acordo com a lista da flora do Brasil (2014), são as primeiras citações para o Estado do Paraná, sendo elas Byttneria urticifolia, Rhamnidium elaeocarpum e ainda Aeschynomene americana L. que é umas das três primeiras citações para o Estado, sendo registrada sua primeira coleta em 2011 por Souza et 
al. (2012) na planície de inundação do alto rio Paraná, e Pereira (2012) na Estação Ecológica do Caiúa.

Segundo a Lista de Espécies da Flora do Brasil (2014), dos táxons reconhecidos até o nível de específico, 95,54\% (236 spp.) são espécies nativas do Brasil e apenas 4,45\% (11 spp.) são espécies exóticas. Dentre estas com potencial de invasoras foram registradas: Impatiens walleriana, Tecoma stans, Ricinus communis, Leucaena leucocephala, Melia azedarac, Morus nigra, Psidium guajava e Eriobotrya japonica, citadas na Lista de Espécies Exóticas Invasoras para o Estado do Paraná (IAP, 2009).

Foram registradas nove espécies que constam em listas (IUCN, 2014; IAP, 2008; MMA, 2008) da flora ameaçada de extinção (Quadro 3). Dessas, apenas Myrocarpus frondosus não foi citada por Pereira (2012), na Estação Ecológica do Caiuá (PEREIRA, 2012), e também Myrcianthes pungens não foi citada por Kita et al. (2007) no Parque do Ingá, e IGPlan (2013) para o Horto Florestal de Maringá.

Quadro 3. Espécies coletas no remanescente florestal da Fazenda Escola do UniCesumar, Maringá, Paraná, ameaçadas ou em perigo de extinção (IUCN - lista vermelha The International Union for Conservation of Nature; BR - Lista Oficial das Espécies da Flora Brasileira Ameaçada de Extinção; PR - Lista Oficial de Espécies da Flora Ameaçadas de Extinção no Paraná

\begin{tabular}{|l|c|c|c|}
\hline Espécie & \multicolumn{3}{|c|}{ Categoria } \\
\hline & IUCN & BR & PR \\
\hline Aspidosperma polyneuron Müll.Arg. & Em perigo & - & Rara \\
\hline $\begin{array}{l}\text { Balfourodendron riedelianum (Engl.) } \\
\text { Engl. }\end{array}$ & Em perigo & - & Rara \\
\hline Casearia gossypiosperma Briq. & - & - & Rara \\
\hline Cedrela fissilis Vell. & Em perigo & - & - \\
\hline Jaracatia spinosa A.DC. & - & - & Rara \\
\hline $\begin{array}{l}\text { Dablstedtia mueblbergiana (Hassl.) M. J. } \\
\text { Silva \& A.M.G. Azevedo }\end{array}$ & - & - & Rara \\
\hline Machaerium paraguariense Hassl. & - & - & Rara \\
\hline Myrocarpus frondosus Allemão & - & - & Rara \\
\hline Myrcianthes pungens (O.Berg.) D.Legrand & Em perigo & - & - \\
\hline
\end{tabular}


Segundo Ortega e Engel (1992), os remanescentes preservados que restaram possuem grande valor ecológico e taxonômico, sendo considerados como uma coleção viva de espécies que representam a flora local e regional e sua diversidade genética, sendo o banco de informações sobre a estrutura, composição e funcionamento do ecossistema.

\section{CONSIDERAÇÕES FINAIS}

Foi encontrada uma grande diversidade florística, similar aos resultados obtidos por outros autores em áreas de domínio de Floresta Estacional Semidecidual presentes no Estado do Paraná, comprovando a semelhança entre estas áreas.

A presença de espécies nativas representa que o remanescente florestal, mesmo com impactos causados por ações antrópicas, conserva espécies importantes e que devem ser preservadas, garantindo a diversidade do local. Além disso, a presença de espécies da flora ameaçadas de extinção reforça a necessidade de preservação da área.

Com isso, o remanescente possui grande importância, constituindo uma importante potencial fonte de propágulos para a dinâmica natural da área no estabelecimento da vegetação, sendo imprescindível que programas de restauração ecológica, formação de corredores ecológicos, controle de espécies exóticas e invasoras sejam realizados neste remanescente, para garantir a conservação e preservação das espécies que o compõem.

\section{REFERÊNCIAS}

APG III. An update of the Angiosperm Phylogeny Group classification for the orders and families of flowering plants: APG III. Botanical Journal of the Linnean Society, v. 161, p. 105-121, 2009.

BATTILANI, J. L.; SCREMIN-DIAS, E.; SOUZA, A. L. T. Fitossociologia de um trecho da mata ciliar do rio da Prata, Jardim, MS, Brasil. Acta Botânica Brasilica. v. 19, n. 
3, p. 597-608, 2005.

BIGARELLA, J. J.; MAZUCHOWSKI, J. Z. Visão integrada da problemática da erosão. ABGE-Associação Brasileira de Geologia e Engenharia: Adea-Associação de Defesa e Educação Ambiental, Maringá, PR, 1985.

BUENO, M. L.; RESENDE, U. M.; GOMES, T. R. Levantamento florístico nas trilhas turísticas da RPPN São Geraldo, Bonito, Mato Grosso do Sul. Revista Brasileira de Biociências, Porto Alegre, v. 5, supl. 2, p. 189-191, 2007.

CAMPOS, E. P.; SILVA, A. F.; MEIRA NETO, J. A. A.; MARTINS, S. V. Florística e Estrutura horizontal da vegetação arbórea de uma ravina em um fragmento florestal no Município de Viçosa, MG. Rev. Árvore, Viçosa-MG, v. 30, n. 6, p. 1045-1054, 2006.

CAMPOS, J. B. A fragmentação de ecossistemas, efeitos decorrentes e corredores de biodiversidade. In: CAMPOS, J. B.; TOSSULINO, M. G. P.; MULLER, C. R. C. (Org.). Unidades de conservação: ações para a valorização da biodiversidade. Curitiba, Instituto Ambiental do Paraná. 2006. p. 165-173.

CARVALHO, D. A. de; OLIVEIRA-FILHO, A. T. de; VILELA, E. A.; CURI, N. Florística e estrutura da vegetação arbórea de um fragmento de Floresta Semidecidual as margens do reservatório da usina hidrelétrica dona rita (Itambé do Mato Dentro, MG). Acta Botanica Brasilica, v. 14, n. 1, p. 37-55, 2000.

CARVALHO, P. E. R. Espécies arbóreas brasileiras. Brasília: Embrapa Informação Tecnológica, Colombo, Embrapa Floresta, 2003. v. 1.

CRONQUIST, A. The evolution and classification of flowering plants. New York: The New York Botanical Garden, 1993. 555p.

DEL QUIQUI, E. M.; MARTINS, S. S.; SILVA, I. C.; BORGHI, W. A.; SILVA, O. H.; SAKURAGUI, C. M.; PACHECO, R. B. Estudo fitossociológico de um trecho da floresta estacional semidecidual em Diamante do Norte, Estado do Paraná, Brasil. Acta Scientiarum Agronomy, Maringá, v. 29, n. 2, p. 283-290, 2007. 
DURIGAN, G.; FRANCO, G. A. D. C.; SAITO, M.; BAITELLO, J. B. Estrutura e diversidade do componente arbóreo da floresta na Estação Ecológica dos Caetetus, Gália, SP. Revista Brasileira de Botânica, v. 23, n. 4, p. 371-383, 2000.

EMBRAPA. Empresa Brasileira de Pesquisa Agropecuária. Atlas do meio ambiente do Brasil. 3. ed. rev. ampl. Brasília: EMBRAPA, 2013. 353p.

erbarioVirtual/ConsultaPublicoHVUC/ResultadoDaConsultaNovaConsulta. do?lingua $=$ PT $>$. Acesso em: jul. 2014.

FACCIULO, D. A. Levantamento florístico de espécies arbóreas presentes na borda do Parque Estadual Mata São Francisco, Paraná. (Curso de Ciências Biológicas) - Universidade Estadual do Norte do Paraná - UENP, 2008. 15p.

FLORA DO BRASIL. Lista de Espécies da Flora do Brasil. 2013. Jardim Botânico do Rio de Janeiro. Disponível em: < http://floradobrasil.jbrj.gov.br/> . Acesso em: ago. 2014.

FONT QUER, P. F. Dicionário de botánica. Barcelona: Labor, 1985. 1244p.

FUNDAÇÃO SOS MATA ATLÂNTICA. Instituto Nacional de Pesquisas Espaciais - INPE. 2009. Atlas dos remanescentes florestais da Mata Atlântica: período de 20052008 - Relatório parcial. São Paulo: Fundação SOS Mata Atlântica e INPE, 2009. 156p.

GOOGLE EARTH. 2014. Disponível em: < http://earth.google.com/> . Acesso em: jul. 2014.

IAP - Instituto Ambiental do Paraná. 2008. Lista oficial de espécies da flora ameaçadas de extinção no Paraná. Disponível em: < http://www.iap.pr.gov.br/ arqui

IAP - Instituto Ambiental do Paraná. 2009. Lista Oficial de Espécies Exóticas Invasoras para o Estado do Paraná. Portaria no 125, de 07 de agosto de 2009. Instituto Ambiental do Paraná, Curitiba. 
IAPAR - INSTITUTO AGRONÔMICO DO PARANÁ. 2014. Monitoramento agroclimático do Paraná. Disponível em: < http:200.201.27.14/Site/Sma/índex. html> Acesso em: jul. 2014.

IGPlan. 2013. Plano de Manejo do Horto Florestal de Maringá. Prefeitura Municipal de Maringá. Maringá.

INTERNATIONAL UNION FOR CONSERVATION OF NATURE - IUCN. 2014. Red List of Threatened Species. Disponível em: <www.iucnredlist.org > Acesso em: jul. 2014.

IPNI. The International Plant Names Index. Disponível em: <http://www.ipni. org/ipni/plantnamesearchpage.do > . Acesso em: jun. 2014.

JUDD, W. S.; CAMPBELL, C. S.; KELLOGG, E. A.; STEVENS, P. F.; DONOGHUE, M. J. Sistemática vegetal: um enfoque filogenético. $3^{\mathrm{a}}$ ed. Tradução de André Olmos Simões... Porto Alegre: Artmed, 2009. 612p.

KITA, K. K.; SOUZA, M. C.; SLUSARSKI, S. R.; LACHNER, D.; MAURI, E. D.; VIANA, L. F.; GARCIA, R. S.; MICHELAN, T. S.; HARTHMAN, V. C.; FONTANA, A. C. Vegetação In: Revisão do Plano de Manejo do Parque Municipal do Ingá. Maringá, 2007. 112p.

LEITAO FILHO, H. F. Considerações sobre a florística de florestas tropicais e subtropicais do Brasil. IPEF, Piracicaba, v. 35, p. 41-46, 1987.

LORENZI, H. Árvores Brasileiras: manual de identificação e cultivo de plantas arbóreas do Brasil. v. 1. 4. ed. Nova Odessa: Editora Instituto Plantarum, 2002, 368p.

LORENZI, H.; SOUZA, H. M.; TORRES, M. A. V.; BACHER, L. B. Árvores exóticas no Brasil: madeiras, ornamentais e aromáticas. Nova Odessa: Instituto Plantarum, 2003, 368p.

MAACK, R. Geografia física do Estado do Paraná. 2. ed. Curitiba: Secretaria da Cultura e do Esporte do Governo do Estado do Paraná. 1981.

MARACAJÁ, P. B.; BATISTA, C. H. F.; SOUSA, A. H.; VASCONCELOS, W. E. Levantamento 
florístico e fitosociológico do extrato arbustivo-arbóreo de dois ambientes na Vila Santa Catarina, Serra do Mel, RN. Revista de Biologia e Ciências da Terra, v. 3, p. 20-33, 2003.

MARANGON, L. C.; SOARES, J. J.; FELICIANO, A. L. P. Florística arbórea da Mata da Pedreira, município de Viçosa, Minas Gerais. Revista Árvore, v. 27, n. 2, p. 207-215, 2003.

MINISTÉRIO DO MEIO AMBIENTE - MMA. 2008. Instrução normativa $n^{\circ}$ 6, de 23 de setembro de 2008. Reconhece espécies da flora ameaçadas de extinção. Diário Oficial da União, no 128, Brasília, 24 set. 2008.

NOGUEIRA-NETO, P. A importância dos pequenos fragmentos florestais. Florestar Estatístico, v. 6, n. 14, p. 7-9, 2003.

ORTEGA, V. R.; ENGEL, V. L. Conservação da biodiversidade de remanescentes de Mata Atlântica na região de Botucatu, SP. Rev. Inst. Flor., São Paulo, v. 4, p. 839-852, 1992.

PEREIRA, G. F. Inventário florístico na Estação Ecológica do Caiuá: formação florestal ripária do Ribeirão Scherer. Exame de Qualificação (Mestrado em Ciências Ambientais), Universidade Estadual de Maringá, Maringá. 2012, 33p.

PEREIRA, M. D.; ALVES, R. R. N. Composição Florística de um remacescente de Mata Atlântica na Área de Proteção Ambiental Barra do Rio Mamanguape, Paraíba, Brasil. Rev. Biol. Cien. Terr, v. 6, n. 1, p. 357-366, 2006.

PINTO, L. P.; BRITO, M. C. W. de. Dinâmica da perda da biodiversidade na Mata Atlântica brasileira: uma introdução. In: GALINDO-LEAL, C.; CÂMARA, I. de G. (eds.). Mata Atlântica: biodiversidade, ameaças e perspectivas. São Paulo: Fundação SOS Mata Atlântica - Belo Horizonte: Conservação Internacional. 2005, p. 27-30.

REFLORA: Virtual Herbarium, 2013. Disponível em: <http://reflora.jbrj.gov.br/ jabot/herbarioVirtual/ConsultaPublicoHVUC/ResultadoDaConsultaNovaConsulta. do?lingua $=$ PT $>$.Acesso em: julho de 2014 
ROSSETTO, E. F. S.; VIEIRA, A. O. S. Vascular Flora of the Mata dos Godoy State Park, Londrina, Paraná, Brazil. Journal of species lists and distribution, Check List, v. 9, n. 5, p. 1020-1034, 2013.

SILVA, A. F.; OLIVEIRA, R. V.; SANTOS, N. R. L.; PAULA, A. Composição Florística e grupos ecológicos das espécies de um trecho de Floresta Semidecidual Submontana da Fazenda São Geraldo, Viçosa-MG. Revista Árvore, Viçosa-MG, v. 27, n. 3, p. 311319, 2003.

SILVA, L. A.; SOARES, J. J. Composição florística de um fragmento de floresta estacional semidecídua no município de São Carlos-SP. Revista Árvore, v. 27, n. 5, p. 647-656. 2003.

SLUSARSKI, S. R.; SOUZA, M. C. Inventário florístico ampliado na mata do Araldo, planície de inundação do alto rio Paraná, Brasil. Revista de estudos ambientais (online), v. 14, p. 14-27, 2012.

SOUZA, M. C. de. Estrutura e composição florística da vegetação de um remanescente florestal da margem esquerda do rio Paraná (Mata do Araldo), Município de Porto Rico, PR. Tese de Doutorado. Universidade Estadual Paulista "Júlio de Mesquita", Rio Claro. 1998. 172p.

SOUZA, M. C. de; KITA, K. K.; ALMEIDA, C. G. de; ROSA, G. S.; SILVA, C. G. da; GARCIA, J. M.; MARTINS, G. L.; SERVILHERI, J. G.; GARCIA, L. M. Vegetação Ripária. In: Universidade Estadual de Maringá. Nupélia/PELD. A planície de inundação do alto rio Paraná: Site 6 PELD/CNPq - Relatório anual 2010. Maringá.

SOUZA, M. C.; MONTEIRO, R. Levantamento florístico em remanescente de floresta ripária no alto rio Paraná: Mata do Araldo, Porto Rico, Paraná, Brasil. Acta Scientiarum Biological Sciensis, v. 27, n. 4, p. 405-414, 2005.

SOUZA, M. C. de; VIANA, L. F.; KITA, K. K.; MIOTTO, S. T. S. O gênero Aeshynomene L. (Leguminosae, Faboideae, Dalvergieae) na planície de inundação do alto rio Paraná, Brasil. Revista Brasileira de Biociências, v. 10, n. 2, p. 198-210, 2012. 
SOUZA, M. C.; CISLINSKI, J.; ROMAGNOLO, M. B. Levantamento florístico. p. 343368. In: Vazzoler, A. E. A. M.; Agostinho, A. A. and Hahn, N. S. (Ed.). A planície de inundação do alto rio Paraná: aspectos físicos, biológicos e socioeconômicos. Maringá: EDUEM, 1997, p. 343-368.

SOUZA, M. C.; KITA, K. K.; SLUSARSKI, S. R.; PEREIRA, G. F. Vascular flora of the Upper Paraná River foodplain. Brazilian Journal of Biology, v. 69, n. 2, p. 735-745, 2009.

SOUZA, M. C.; ROMAGNOLO, M. B.; KITA, K. K. Riparian vegetation: ecotones and plant communities. In: THOMAZ, S. M.; AGOSTINHO, A. A.; HAHN, N. S. (Org.). The upper River Paraná and its floodplain: physical aspects, ecology and conservation. Leiden: Backhuys Publishers, 2004, p. 352-367.

STRANGHETTI, V.; ITURALDE, R. B.; GIMENEZ, L. R.; ALMELLA, D. Florística de um fragmento florestal do sítio São Pedro, município de Potirendaba, Estado de São Paulo. Acta Scientiarum Biological Sciences, Maringá, v. 25, p. 67-172, 2003.

THE PLANT LIST. 2013. Version 1. Published on the Internet. Disponível em: < http://www.theplantlist.org/> . Acesso em: jul. 2014.

VACCARO, S.; LONGHI, S. J.; BRENA, D. A. Aspectos da composição florística e categorias sucessionais do estrato arbóreo de três subseres de uma floresta estacional decidual, no município de Santa Tereza-RS. Revista Ciência Florestal, v. 9, n. 1, p. $1-18,1999$.

VEIGA, M. P.; MARTINS, S. S.; SILVA, I. C.; TORMENTA, C. A.; SILVA, O. H. Avaliação dos aspectos florísticos de uma mata ciliar no Norte do Estado do Paraná. Acta Scientiarum. Agronomy, Maringá, v. 25, n. 2, p.519-525, 2003

ZIPPARRO, V. B.; GUILHERME, F. A. G.; ALMEIDA-SCABBIA, R. J.; MORELLATO, L. P. C. Levantamento florístico de Floresta Atlântica no sul do Estado de São Paulo, Parque Estadual Intervales, Base Saibadela. Biota Neotrop, Campinas, v. 5, p. 147 $170,2005$. 
532 Flora vascular de um remanescente de floresta estacional semidecidual, no município de...

Recebido em: 09 de abril de 2015 Aceito em: 23 de março de 2016 